\title{
Impact of closed-system drug transfer device on exposure of environment and healthcare provider to cyclophosphamide in Japanese hospital
}

Tomohiro Miyake ${ }^{1,2}$, Takuya Iwamoto ${ }^{2,3}$, Manabu Tanimura ${ }^{1}$ and Masahiro Okuda ${ }^{2,3^{*}}$

\begin{abstract}
In spite of current recommended safe handling procedures, the potential for the exposure of healthcare providers to hazardous drugs exists in the workplace. A reliance on biological safety cabinets to provide total protection against the exposure to hazardous drugs is insufficient. Preventing workplace contamination is the best strategy to minimize cytotoxic drug exposure in healthcare providers. This study was conducted to compare surface contamination and personnel exposure to cyclophosphamide before and after the implementation of a closedsystem drug transfer device, PhaSeal, under the influence of cleaning according to the Japanese guidelines. Personnel exposure was evaluated by collecting $24 \mathrm{~h}$ urine samples from 4 pharmacists. Surface contamination was assessed by the wiping test. Four of 6 wipe samples collected before PhaSeal indicated a detectable level of cyclophosphamide. About 7 months after the initiation of PhaSeal, only one of 6 wipe samples indicated a detectable level of cyclophosphamide. Although all 4 employees who provided urine samples had positive results for the urinary excretion of cyclophosphamide before PhaSeal, these levels returned to minimal levels in 2 pharmacists after PhaSeal. In combination with the biological safety cabinet and cleaning according to the Japanese guidelines, PhaSeal further reduces surface contamination and healthcare providers exposure to cyclophosphamide to almost undetectable levels.
\end{abstract}

Keywords: Cyclophosphamide, Surface contamination, exposure of healthcare provider, PhaSeal, Japanese guidelines

\section{Background}

Many drugs used in the treatment of cancer are considered to be hazardous to healthcare workers. Over the last 20 years, several studies have reported environmental contamination with hazardous drugs in hospital pharmacies (Castiglia et al. 2008; Ensslin et al. 1994; Hedmer et al. 2008; McDevitt et al. 1993; Sessink et al. 1992; Sessink et al. 1995; Sugiura et al. 2011; Vandenbroucke and Robays 2001; Yoshida et al. 2011). In addition, hazardous drugs were inadvertently absorbed, as determined by the presence of parent compounds and/or their metabolites in the urine of health care workers (Ensslin et al. 1997; Schreiber et al. 2003; Sessink et al. 1992; Sessink et al.

\footnotetext{
* Correspondence: okudam@clin.medic.mie-u.ac.jp

2Department of Clinical Pharmacy and Biopharmaceutics, Mie University Graduate School of Medicine, Mie, Japan

${ }^{3}$ Department of Pharmacy, Mie University Hospital, Mie, Japan Full list of author information is available at the end of the article
}

1994; Sessink et al. 1997). Due to the potential health risks of hazardous drugs, the increasing use of these drugs, and continuing environmental contamination, the National Institute for Occupational Safety and Health $(\mathrm{NIOSH})$ published an alert for antineoplastic and other hazardous drugs used in healthcare settings (National Institute for Occupational Safety and Health NIOSH 2004). Based upon recommendations, the American Society of Health-System Pharmacists (ASHP) and the International Society of Oncology Pharmacy Practitioners (ISOPP) have published updated guidelines on the safe-handling of cytotoxic and hazardous drugs (American Society of Health-System Pharmacists guidelines on handling hazardous drugs 2006; International Society of Oncology Pharmacy Practitioners Standards Committee. ISOPP standards of practice 2007).

In Japan, guidelines for handling antineoplastic drugs in hospitals were issued by the Japan Pharmaceutical 
Association in 1991, which was updated in 1994. Furthermore, these guidelines were revised and published as "Compounding Manuals for Antineoplastic Agents" in 2005 and 2009 (Kitada et al.). The Japanese Society of Hospital Pharmacists (JSHP) academic committee then updated and published the "Guidelines for Compounding Antineoplastic Agents," referring to the "ALERT" in "Preventing Occupational Exposure to Antineoplastic and Other Hazardous Drugs in Health Care Settings" announced by the NIOSH and guidelines from the ASHP.

Introduction of the biological safety cabinet (BSC) for the preparation of anticancer drugs is limited, with only $35.2 \%$ of hospitals using the BSC in Japan, even though guidelines on the preparation of anticancer drugs exist (JSHP. 2012). Recently, the advantage of closed-system drug transfer device (CSTD) is recognized to prevent or reduce exposure of healthcare providers from hazardous drugs. The CSTD is a device that mechanically prevents contamination of the environmental substances into a drug solution and the escape of hazardous drug or vapor concentrations outside the system. In addition, only $10.7 \%$ of hospitals in Japan currently use the CSTD (JSHP. 2012), although pharmacists in $90 \%$ or more of hospitals recognize the usefulness of the CSTD. Reimbursement of technical fees for the use of CSTD to the medical institutions under the medical insurance system were introduced in 2010, and the value was raised in 2012 for the preparation of volatile anticancer drugs, i.e. cyclophosphamide, ifosfamide and bendamustine; therefore, the use of the CSTD in a hospital setting has been increasing in Japanese hospitals. Interestingly, there is no authorized pharmacy technician system in Japan, and, as such, pharmacists are regarded as being primarily in charge of compounding hazardous drugs.

At Yamada Red Cross Hospital (current name: Ise Red Cross Hospital), we developed institutional manuals for compounding anticancer drugs in reference to the above guidelines and began to use BSC Class IIB2 and personal protective equipment (PPE) in the compounding room of the pharmacy department. Each pharmacist in charge of compounding anticancer drugs wear two layers of gloves, a disposable polypropylene gown with long sleeves and closed fronts, a disposable cap and a disposable surgical mask. In addition, the BSC and floor of the compounding room are wiped after compounding according to the Japanese guidelines. However, we revealed that cyclophosphamide $(\mathrm{CP})$ was still detected at the sites of the wipe tests as well as in urine samples from all pharmacists in charge of CP compounding (Tanimura et al. 2009). Several studies have shown nearly complete containment or reduction in surface contamination accompanying preparation and/or administration of hazardous drug (Connor et al. 2002; Vandenbroucke and Robays 2001; Wick et al. 2003).
We conducted this study to evaluate the effects of the CSTD on surface contamination and exposure of pharmacists in charge of compounding $\mathrm{CP}$ in a Japanese hospital setting.

\section{Materials and methods}

Yamada Red Cross Hospital is a community hospital in Mie prefecture Japan with 655 beds for inpatients designated for the treatment of cancer. In the hospital, 7061 patients were treated with anticancer agents in the year 2010. The study design was approved by the Institutional Review Board at Yamada Red Cross Hospital and all subjects provided written.

\section{Wipe tests}

A total of 6 sites in the anticancer drugs compounding room of the pharmacy were subjected to wipe tests for CP (Shionogi \& Co., Ltd., Osaka, Japan) contamination on September 7, 2007 (first test) using Cyto Wipe Kits (Exposure Control B.V., Al Wijchen, Netherlands). On April 2008, we began to use the CSTD (PhaSeal ${ }^{\circledR}$; Carmel Pharma ab, Goteborg, Sweden), and then the same tests were conducted on March 4, 2009 (second test) eleven months after the implementation of PhaSeal. The same pharmacist collected the wipe samples, and this study was faithfully done according to the wipe manual. The test sites were: 1 . work surface of the BSC; 2 . airfoil inside the $\mathrm{BSC}$; 3 . the floor in front of the $\mathrm{BSC}$; 4 . the central work table; 5 . the work table with a telephone and personal computer in the office area; and 6. the floor of the entrance into the compounding room (Figure 1). We wiped exactly the same position of surface before and after implementation of PhaSeal by assuring the distance from the edge of the wall and the table. All wipe samples were taken at the end of the routine preparation of hazardous drugs before daily cleaning. We used $0.03 \mathrm{M}$ sodium hydroxide, $2 \%$ sodium hypochlorite, and $1 \%$ sodium thiosulfate to wipe clean the surface of BSC. The floors of the room were cleaned using disposable sheets, which were dampened with ethanol and detergent. The tables were wiped using a disposable nonwoven rayon fabric dampened with ethanol. The floors and tables of the room were wiped every day.

Cyto Wipe Kits were used for all sampling. These kits contained standardized supplies for taking samples, including certified drug-free sampling tissues, dropper bottles containing sampling solution, storage containers, latex gloves, and labels. Each predetermined sampling location was marked with colored tape and measured to determine the sample area. All sample containers were pre-labeled with the collection date and a coded number that identified the study site and sample location. 


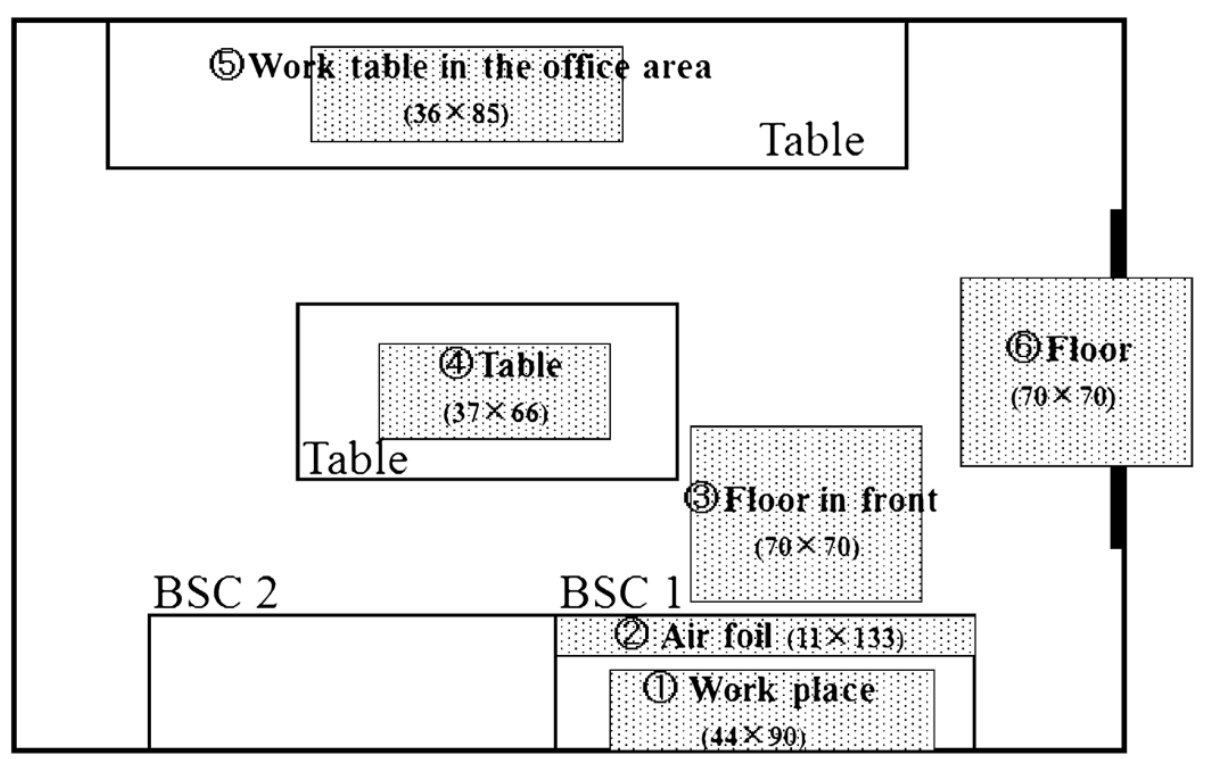

Figure 1 Sites of the wipe test in the chemotherapy preparation room at the pharmacy.

\section{Urine test}

Four pharmacists (3 males and 1 female) who compounded $\mathrm{CP}$ collected their own urine samples over $24 \mathrm{~h}$. It would be collected for $24 \mathrm{~h}$ during the period of August 30 through September 11, 2007 based on the schedule of the pharmacist. These pharmacists collected urine samples at every urination from prior to compounding anticancer drugs to the next morning. More than 7 months after the initiation of PhaSeal, urine samples were collected again from the same 4 pharmacists between November 7, 2008 and March 17, 2009.

As stipulated in the instruction manual, we collected samples using Cyto Urine Kits (Exposure Control B.V., Al Wijchen, Netherlands). Using measuring cups, we took urine samples from the test pharmacists. The sampling times and volume of urine were recorded. We placed $5 \mathrm{~mL}$ of the urine collected into a plastic container with a screw-on lid. The containers were stored in a freezer at -80 degrees $\mathrm{C}$. The amount of $\mathrm{CP}$ prepared by these pharmacists on the day of the urine test was also recorded. All 4 pharmacists did not take any medicines that may have influenced CP metabolism.

\section{Analysis of samples}

Frozen wipe and urine samples were transported with dry ice to Exposure Control for determination of $\mathrm{CP}$ level. Samples were analyzed with a Varian Saturn 4D GC-MS/MS ion-trap system with a Varian 8200 auto sampler, controlled by a computer. The detection limits of intact CP were $0.10 \mathrm{ng} / \mathrm{mL}$ for the wipe test and $0.01 \mathrm{ng} / \mathrm{mL}$ for the urine test.

\section{Results}

\section{Wipe tests}

The results of the wipe tests were shown in Table 1 . The contamination per $\mathrm{cm}^{2}$ was calculated. Before PhaSeal, $\mathrm{CP}$ was detected at 4 test sites in the compounding room in the pharmacy: 1 . the work surface; 2 . airfoil inside the BSC; 3 . the floor in front of the BSC; 6 . the floor of the entrance to the compounding room. After the installation of PhaSeal, CP was not detected in any other locations except for the floor of the entrance to the compounding room.

\section{Urine test}

The mean amount of CP compounded by pharmacists on the day of the urine test after the installation of PhaSeal was $11.9 \%$ (3945 mg) higher than that before the installation of PhaSeal (3525 mg). Before PhaSeal, 34 urine samples were collected from four pharmacists, and $\mathrm{CP}$ was detected in 26 samples. The total amount of CP excreted in each pharmacist was 34.9, 27.0, 56.5, and $71.3 \mathrm{ng} / 24 \mathrm{~h}$ (Table 2), respectively, with mean value $47.4 \mathrm{ng} / 24 \mathrm{~h}$. After PhaSeal, 31 urine samples were collected from the same four pharmacists, and CP was detected in two urine samples only from two pharmacists. The total amount of CP in these samples was 6.4 and $7.8 \mathrm{ng} / 24 \mathrm{~h}$, respectively, with mean value $3.6 \mathrm{ng} /$ 24 h (Table 2).

\section{Discussion}

Several steps in the compounding anticancer drugs create conditions that may allow the escape of the drug into the compounding room as well as the work surface of 
Table 1 Concentration of $\mathrm{CP}$ in wipe samples $\left(\mathrm{ng} / \mathrm{cm}^{2}\right)$ in the preparation on room

\begin{tabular}{|c|c|c|c|c|c|c|c|c|}
\hline \multirow[b]{2}{*}{ Sample } & \multirow[b]{2}{*}{ Description spot } & \multirow[b]{2}{*}{ Area $\left(\mathrm{cm}^{2}\right)$} & \multicolumn{3}{|c|}{ First test } & \multicolumn{3}{|c|}{ Second test } \\
\hline & & & $\begin{array}{l}\mathrm{ng} / \mathrm{mL} \\
\text { (NaOH) }\end{array}$ & $\mathrm{ng}$ & $\mathrm{ng} / \mathrm{cm}^{2}$ & $\begin{array}{l}\mathrm{ng} / \mathrm{mL} \\
(\mathrm{NaOH})\end{array}$ & $\mathrm{ng}$ & $\mathrm{ng} / \mathrm{cm}^{2}$ \\
\hline 1 & Work place & 3900 & 0.28 & 45 & 0.012 & nd & - & - \\
\hline 2 & Air foil & 1463 & 0.54 & 86 & 0.059 & nd & - & - \\
\hline 3 & Floor in front & 4900 & 0.17 & 27 & 0.006 & nd & - & - \\
\hline 4 & Table & 2442 & nd & - & - & nd & - & - \\
\hline 5 & Office area & 3060 & nd & - & - & nd & - & - \\
\hline 6 & Floor & 4900 & 0.15 & 24 & 0.005 & 0.24 & 38 & 0.008 \\
\hline
\end{tabular}

nd not detected. The first test was conducted on September 7, 2007. The second test was conducted on March 4, 2009. The contamination per $\mathrm{cm}^{2}$ was calculated assuming $100 \%$ recovery and wipe efficiency. The detection limit for cyclophosphamide was $0.10 \mathrm{ng} / \mathrm{mL} \mathrm{NaOH}$. PhaSeal ${ }^{\circledR}$ was not used for the first test, and was used for the second.

BSC. A common source of contamination is the formation of an aerosol due to over or under pressure inside the drug vial. An aerosol forms when the vial membrane is punctured and the air pressure within the vial quickly equalizes with ambient air pressure. The aerosol settles on work surfaces and other exposed areas in the immediate environment. Working with hazardous drugs in health care settings has demonstrated measurable urine concentrations accompanied within fertility, miscarriage, and birth defects (Selevan et al. 1985; Valanis et al. 1997; Valanis et al. 1999). Cautionary reports described that lymphocyte DNA damage and chromosome 5 and 7 abnormalities may be induced in healthcare providers handling hazardous drugs (McDiarmid et al. 2010; Sasaki et al. 2008; Yoshida et al. 2006). Although the BSC may reduce environmental contamination by an aerosol and spills of hazardous drugs, it cannot completely prevent environmental contamination.

The Japanese guideline "Guideline for aseptic handling of injection and antineoplastic drugs" was developed referring to the guidelines of the ASHP and ISOPP (Nabeshima et al. 2008). In addition to the use of the CSTD, cleaning of the BSC is also recommended. We reported that $\mathrm{CP}$ was detected in 4 wipe samples with the mean $\mathrm{CP}$ concentration being $0.014 \mathrm{ng} / \mathrm{cm}^{2}$ before PhaSeal was used; however, CP was detected in only 1 wipe sample at $0.001 \mathrm{ng} / \mathrm{cm}^{2}$ after PhaSeal was installed. The mean amount of CP in urine samples was also reduced to $7.1 \%$ with PhaSeal relative to that before PhaSeal. There are three features in our study. 1; The training of pharmacists to use PhaSeal. In the present study, the effect of PhaSeal was evaluated more than 7

Table 2 Total amount of CP in urine samples ( $\mathrm{ng} / 24 \mathrm{~h}$ ) from four pharmacists

\begin{tabular}{|c|c|c|c|c|c|}
\hline Pharmacist & Amount of CP prepared (mg/day) & Number of samples & Number of positive samples & Detection rate (\%) & CP (ng/24 h) \\
\hline \multicolumn{6}{|c|}{ First test (before PhaSeal ${ }^{\circledR}$ ) } \\
\hline 1 & 2900 & 10 & 7 & 70.0 & 34.9 \\
\hline 2 & 2810 & 9 & 6 & 66.7 & 27.0 \\
\hline 3 & 3530 & 8 & 6 & 75.0 & 56.5 \\
\hline 4 & 4860 & 7 & 7 & 100.0 & 71.3 \\
\hline Mean & 3525 & 8.5 & 6.5 & 77.9 & 47.4 \\
\hline \multicolumn{6}{|c|}{ Second test (after PhaSeal ${ }^{\circledR}$ ) } \\
\hline 1 & 3000 & 8 & 0 & 0.0 & nd \\
\hline 2 & 4600 & 7 & 0 & 0.0 & nd \\
\hline 3 & 3700 & 8 & 1 & 12.5 & 6.4 \\
\hline 4 & 4480 & 8 & 1 & 12.5 & 7.8 \\
\hline Mean & 3945 & 7.8 & 0.5 & 6.3 & 3.6 \\
\hline
\end{tabular}

The first test was conducted between August 30 and September 11, 2007.

The second test was conducted between November 7, 2008 and March 17, 2009.

The amount of CP prepared was measured on the day of the urine test.

PhaSeal ${ }^{\circledR}$ was not used for the first test, and was used for the second test. 
months after the implementation of PhaSeal. The importance of training for using the CSTD has also been described in the guidelines of the ISOPP (International Society of Oncology Pharmacy Practitioners Standards Committee. ISOPP standards of practice 2007). 2; Method of cleaning the environment. There is an increased risk of inhaling $\mathrm{CP}$ when the inside of the BSC being cleaned with ethanol (Pethran et al. 2003). We prevented the inhalation of hazardous drugs by cleaning the compounding room according to the Japanese guideline (Nabeshima et al. 2008). The inside of the BSC was wiped down 4 times with gauze, which were consecutively moistened with $0.03 \mathrm{M} \mathrm{NaOH}, 2 \%$ sodium hypochlorite, $1 \%$ sodium thiosulfate, and $80 \%$ ethanol (Mochizuki et al. 2008). The floor was also cleaned using disposable sheets every day. 3; Analysis of samples. Our samples were measured by Exposure Control. A few wipe samples were collected in this study, because of the small number of pharmacists and limited budget for the cost of analytical methods. Therefore, our results were shown by the mean value. However our result indicates that exposure to $\mathrm{CP}$ is decreased by using PhaSeal and cleaning the BSC and floor according to the guidelines.

In the US, four quantitative studies have been conducted to evaluate the use of PhaSeal in reducing contamination of the workplace with hazardous drugs (Connor et al. 2002; Harrison et al. 2006; Nyman et al. 2007; Wick et al. 2003). Sessink et al. tested PhaSeal in 22 US hospitals and concluded that a marked reduction in environmental contamination could be achieved if the compounding was performed using PhaSeal (Sessink et al. 2011). In Japan, Yoshida reported that $\mathrm{CP}$ was detected in all wipe samples, and also indicated that the mean amount of $\mathrm{CP}$ in urine samples after the installation of PhaSeal (Yoshida et al. 2009). These reports are comparable with our current study that reduction of healthcare provider exposure to hazardous drugs was achieved by standard handling of the drug with the CSTD in accordance with Japanese guidelines.
Our results show that a reduction in environmental contamination can be achieved if the preparation is performed by using PhaSeal. However, even with the use of the PhaSeal, environmental contamination was still observed. Possible sources contributing to this observation may include remaining contamination from the past and introduction of new contamination via external contamination on the drug vials. Hedmer et al. (2005) and Connor et al. (2005) had been published showing surface contamination of antineoplastic drug vials. While our current study show reduction in contamination, it was difficult to evaluate exactly whether PhaSeal completely prevent the exposure of healthcare professionals to $\mathrm{CP}$ because significant amount of $\mathrm{CP}$ may be carried in from the package surface of $\mathrm{CP}$ during compounding.

Up to $25 \%$ of $\mathrm{CP}$ administered is excreted in the urine as an unchanged form for $24 \mathrm{~h}$, and more than $50 \%$ of $\mathrm{CP}$ is metabolized to 4-ketocyclophosphamide and carboxyphosphamide via 4-hydroxycyclophosphamide by cytochrome P450 and oxidase in the liver (Fujita Fujita 1986). Tanimura et al. (2009) reported that $0.24 \mathrm{ng} / \mathrm{mL} \mathrm{CP}$ was detected at $26 \mathrm{~h}$ after compounding $\mathrm{CP}$. It is obvious that detectable levels of $\mathrm{CP}$ and its metabolites are still present in the urine of the pharmacists. Since exposure to $\mathrm{CP}$ over a long period of time may increase the risk of the accumulation of its metabolites in the body, further studies are needed to clarify the exposure evaluation including the urinary metabolized CP level. Sessink described the risk of developing additional cancer due to systematic exposure to CP in his report (Sessink et al. 1995). By extra polating animal studies to patient data, the calculated chance of developing additional cancer was between 1.4 and 10 additional cancer cases per year per million workers when exposed daily to $\mathrm{CP}$ with a urinary excretion value of $180 \mathrm{ng} / 24 \mathrm{~h}$. When applied to our results, the risk of developing additional cancer due to occupational exposure to CP is shown in Table 3. Our results indicated that the risk of developing additional cancer could be reduced by the combined use of the BSC and CSTD.

Our results also indicated that the PhaSeal system and cleaning the environment reduced the exposure of

Table 3 The risk of developing additional cancer due to occupational exposure to CP

\begin{tabular}{|c|c|c|c|c|c|}
\hline \multicolumn{3}{|c|}{ First test (before PhaSeal ${ }^{\circledR}$ ) } & \multicolumn{3}{|c|}{ Second test (after PhaSeal ${ }^{\circledR}$ ) } \\
\hline Pharmacist & $\mathrm{CP}(\mathrm{ng} / 24 \mathrm{~h})$ & Cancer risk $^{*}$ & Pharmacist & CP (ng/24 h) & Cancer risk \\
\hline 1 & 34.9 & $0.27-1.94$ & 1 & nd & - \\
\hline 2 & 27.0 & $0.21-1.50$ & 2 & nd & - \\
\hline 3 & 56.5 & $0.44-3.14$ & 3 & 6.4 & $0.05-0.36$ \\
\hline 4 & 71.3 & $0.55-3.96$ & 4 & 7.8 & $0.06-0.43$ \\
\hline
\end{tabular}

nd: not detected.

The first test was conducted on September 12, 2007

The second test was conducted on March 18, 2009.

*Cancer risk: extra cancer cases in a million workers each year. 
employees to $\mathrm{CP}$ and its surface contamination in the setting of a Japanese hospital. Therefore, the continuous monitoring of personnel and the environment contamination is necessary to evaluate newly-installed procedures and the long-term effects of its procedures.

\section{Conclusion}

In combination with cleaning according to the Japanese guidelines, PhaSeal further reduces surface contamination and healthcare provider exposure of $\mathrm{CP}$ could be achieved at almost undetectable levels.

\section{Abbreviations}

ASHP: American Society of Health-System Pharmacists; BSC: Biological safety cabinet; CP: Cyclophosphamide; CSTD: Closed-system drug transfer device; ISOPP: International Society of Oncology Pharmacy Practitioners; JSHP: Japanese Society of Hospital Pharmacists; NIOSH: National Institute for Occupational Safety and Health; PPE: Personal protective equipment.

\section{Competing interests}

All authors declare that they have no competing interests.

\section{Authors' contributions}

TM carried out all experiments and interpreted data and drafted the manuscript; TI, MT and MO supervised experiments and revised the manuscript. All authors read and approved the final manuscript.

\section{Author details}

${ }^{1}$ Department of Pharmacy, Ise Red Cross Hospital, Mie, Japan. ${ }^{2}$ Department of Clinical Pharmacy and Biopharmaceutics, Mie University Graduate School of Medicine, Mie, Japan. ${ }^{3}$ Department of Pharmacy, Mie University Hospital, Mie, Japan.

\section{Received: 18 April 2013 Accepted: 12 June 2013}

Published: 21 June 2013

\section{References}

ASHP (2006) ASHP guidelines on handling hazardous drugs. Am J Health Syst Pharm 63:1172-1193

Castiglia L, Miraglia N, Pieri M, Simonelli A, Basilicata P, Genovese G, Guadagni R, Acampora A, Sannolo N, Scafarto MV (2008) Evaluation of occupational exposure to antiblastic drugs in an Italian hospital oncological department. J Occup Health 50:48-56

Connor TH, Anderson RW, Sessink PJM, Spivey SM (2002) Effectiveness of a closed-system device in containing surface contamination with cyclophosphamide and ifosfamide in an i.v. admixture area. Am J Health-Syst Pharm 59:68-72

Connor TH, Sessink PJM, Harrison BR, Pretty JR, Peters BG, Alfaro RM, Bilos A Beckmann G, Bing MR, Anderson LM, DeChristoforo R (2005) Surface contamination of chemotherapy drug vials and evaluation of new vialcleaning techniques: Results of three studies. Am J Health-Syst Pharm 62:475-484

Ensslin AS, Huber R, Pethran A, Römmelt H, Schierl R, Kulka U, Fruhmann G (1997) Biological monitoring of hospital pharmacy personnel occupatonally exposed to cytostatic drugs: urinary excretion and cytogenetics studies. Int Arch Occup Environ Health 70:205-208

Ensslin AS, Stoll Y, Pethran A, Pfaller A, Rommelt H, Fruhmann G (1994) Biological monitoring of cyclophosphamide and ifosfamide in urine of hospital personnel occupationally exposed to cytostatic drugs. Occup Environ Med 51:229-233

Fujita H (1986) Alkylating agents (section 2), pharmacokinetics of antineoplastic drugs. Medical Review, Japan

Harrison B, Peters BG, Bing MR (2006) Comparison of surface contamination with cyclophosphamide and fluorouracil using a closed-system drug transfer deviceversus standard preparation techniques. Am J Health-Syst Pharm 63:1736-1744

Hedmer M, Georgiadi A, Bremberg ER, Jonsson BAG, Eksborg S (2005) Surface contamination of Cyclophosphamide packaging and surface contamination with antineoplastic drugs in a hospital pharmacy in Sweden. Ann occupHyg 49:629-637

Hedmer M, Tinnerberg H, Axmon A, Jonsson BAG (2008) Environmental and biological monitoring of antineoplastic drugs in four workplaces in a Swedish hospital. Int Arch Occup Environ Health 81:899-911

International Society of Oncology Pharmacy Practitioners Standards Committee. ISOPP standards of practice (2007) Safe handling of cytotoxics. J Oncol PharmPract 13:1-81

Kitada M, Katou H, Nakayama S, Hama T, Sugiura S (2009) The revised version of guideline of handling antineoplastic drugs in medical center-Manual of handling antineoplastic drugs. YakujiNippo Co, Tokyo, Japan

McDevitt JJ, Lees PS, McDiarmad MA (1993) Exposure of hospital pharmacists and nurses to antineoplastic agents. J Occup Med 35:57-60

McDiarmid MA, Oliver MS, Roth TS, Rogers B, Escalante C (2010) Chromosome 5 and 7 abnormalities in oncology personnel handling anticancer drugs. JOEM 52:1028-1034

Mochizuki C, Fijikawa I, Tei G, Yoshida J (2008) A comparison of cleaning solutions in the biological safety cabinet for preparation of anti-cancer agents. J Jpn Soc Hosp Pharm 44:601-604

Nabeshima T, Sugiura S, Nakanishi H, Tanimura M, Hashida T, Syoji T, Nakao M (2008) Guideline for aseptic handling of injection and antineoplastic drugs. YakujiNippo Co., Tokyo, Japan

National Institute for Occupational Safety and Health (NIOSH) (2004) NIOSH ALERT (2004) preventing occupational exposures to antineoplastic and other hazardous drugs in healthcare settings, Department of Health and Human Service (DHHS)., http://www.cdc.gov/niosh/docs/2004-165/pdfs/

Nyman HA, Jorgenson JA, Slawson MH (2007) Workplace contamination with antineoplastic agents in a NEW cancer hospital using a closed-system drug transfer device. Hospital Pharmacy 42:219-225

Pethran A, Schierl R, Hauff K, Grimm CH, Boos KS, Nowak D (2003) Uptake of antineoplastic agents in pharmacy and hospital personnel. Part 1: monitoring of urinary concentrations. Int Arch Occup Environ Health; 76:5-10

Sasaki M, Dakeishi M, Hoshi S, Ishii N, Murata K (2008) Assessment of DNA damage in Japanese nurses handling antineoplastic drugs by the comet assay. J Occup Health 50:7-12

Schreiber C, Radon K, Pethran A, Schierl R, Hauff K, Grimm CH, Boos KS, Nowak D (2003) Uptake of antineoplastic agents in pharmacy personnel. Part II: study of work-related risk factofs. Int Arch Occup Environ Health 76:11-16

Selevan SG, Lindbohm M-L, Hornung RW, Hemminki K (1985) A study of occupational exposure to antineoplastic drugs and fetal lossin nurses. N Engl J Med 313:1173-1178

Sessink PJM, Anzion RB, Van Den Broek PHH, Bos RP (1992) Detection of contamination with antineoplastic agents in a hospital pharmacy department. Pharm Week Sci 14:16-22

Sessink PJM, Boer KA (1992) Scheefhals APH. Anzion RBM, Bos RP (1992) Occupational exposure to antineoplastic agents at several departments in a hospital. Int Arch Occup Environ Health 64:105-112

Sessink PJM, Connor TH, Jorgenson JA, Tyler TG (2011) Reduction in surface contamination with antineoplastic drugs in 22 hospital pharmacies in the US following implementation of a closed-system drug transfer device. J Oncol Pharm Practice 17:39-48

Sessink PJM, Kroese ED, Kranen HJ, Bos RP (1995) Cancer risk assessment for health care workers occupationally exposed to cyclophosphamide. In Arch Occup Environ Health 67:317-323

Sessink PJM, Van De Kerkhof MCA, Anzion RBM, Noordhoek J, Bos RP (1994) Environmental contamination and assessment of exposure to antineoplastic agents by determination of cyclophosphamide in urine of exposed pharmacy technicians: Is skin absorption an important exposure route? Arch Environ Health 49:165-169

Sessink PJM, Wittenhorst BCJ, Anzion RBM, Bos RP (1997) Exposure of pharmacy technicians to antineoplastic agents: Reevaluation after additional protective measures. Arch Environ Health 52:240-244

Sugiura S, Nakanishi H, Asano M, Hashida T, Tanimura M, Hama T, Nabeshima T (2011) Multicenter study for environmental and biological monitoring of occupational exposure to cyclophosphamide in Japan. J Oncol Pharm Practice 17:20-28

Tanimura M, Yamada K, Sugiura S, Mori K, Nagata H, Tadokoro K, Miyake T, Hamaguchi Y, Sessink PJM, Nabeshima T (2009) An environmental and biological study of occupational exposure to cyclophosphamide in the pharmacy of a Japanese community hospital designated for the treatment of cancer. J Health Sci 55:750-756 
The Japanese society of hospital pharmacists (2012) J Jpn Soc Hosp 48:501-556

Valanis B, Vollmer W, Labuhn K, Glass A (1997) Occupational exposure to antineoplastic agents and self-reported infertility among nurses and pharmacists. J Occup Environ Med 39:574-580

Valanis B, Vollmer WM, Steele P (1999) Occupational exposure to antineoplastic agents: self-reported miscarriages and stillbirths among nurses and pharmacists. J Occup Environ Med 41:632-638

Vandenbroucke J, Robays H (2001) How to protect environment and employees against cytotoxic agents, the UZ Ghent experience. J Oncol Pharm Practice 6:146-152

Wick C, Slawson MH, Jorgenson JA, Tyler LS (2003) Using a closed-system protective device to reduce personnel exposure to antineoplastic agents. Am J Health-Syst Pharm 60:2314-2320

Yoshida J, Koda S, Nishida S, Yoshida T, Miyajima K, Shinji K (2011) Association between occupational exposure levels of antineoplastic drugs and work environment in five hospitals in japan. J Oncol Pharm Practice 17:29-38

Yoshida J, Kosaka H, Tomioka K, Kumagai S (2006) Genotoxic risk to nurses from contamination of the work environment with antineoplastic drugs in japan. J Occup Health 48:517-522

Yoshida J, Tei G, Mochizuki C, Masu Y, Koda S, Kumagai S (2009) Use of a closed system device to reduce occupational contamination and exposure to antineoplastic drugs in the hospital work environment. Ann OccupHyg 53:153-160

doi:10.1186/2193-1801-2-273

Cite this article as: Miyake et al:: Impact of closed-system drug transfer device on exposure of environment and healthcare provider to cyclophosphamide in Japanese hospital. SpringerPlus 2013 2:273.

\section{Submit your manuscript to a SpringerOpen ${ }^{\circ}$ journal and benefit from:}

- Convenient online submission

- Rigorous peer review

- Immediate publication on acceptance

- Open access: articles freely available online

- High visibility within the field

- Retaining the copyright to your article

Submit your next manuscript at $\gg$ springeropen.com 